\title{
Diferenças nas Percepções de Crianças sobre Cuidado Parental Real e Ideal Quando Pais Vivem Juntos ou Separados
}

\author{
Differences in Children Perceptions about Real and Ideal Parental Care When \\ Parents are Married or Separated
}

\author{
Everley Rosane Goetz \& Mauro Luis Vieira* \\ Universidade Federal de Santa Catarina, Florianópolis, Brasil
}

\begin{abstract}
Resumo
Esta pesquisa teve como objetivo principal identificar se os filhos cujos pais vivem juntos percebem diferenças no cuidado parental (real e ideal) em relação àqueles cujos pais são separados. Participaram do estudo 213 crianças, de duas escolas da rede municipal de ensino de Florianópolis, com faixa etária compreendida entre 10 e 11 anos. Os instrumentos utilizados foram dois questionários, contendo perguntas fechadas. Os resultados indicam diferenças estatisticamente significativa entre a percepção que os filhos têm do pai real em relação ao ideal, quando os pais não vivem juntos. A percepção da mãe real está mais próxima da ideal nos dois casos: de crianças que vivem com pai e mãe e de crianças cujos pais são separados. Como conclusão geral, pode-se afirmar que as crianças percebem o pai real bastante afastado do ideal em aspectos referentes ao cuidado e à interação, principalmente quando os pais são separados.

Palavras-chave: Percepção; filhos; cuidado parental; sistêmica.
\end{abstract}

\begin{abstract}
The main objective of the present study is to identify if the children whose parents live together perceive differences concerning parental care (both real and ideal) in relation to those whose parents are separated. Two hundred and thirteen children altogether, regularly enrolled at municipal schools of Florianópolis, Brasil aged 10-11 years old, and participated of the study. Two questionnaires, which contained closed questions, were used. The results indicate significant statistic differences between the perception children have of the real father in relation to the ideal father when the parents do not live together. In relation to the mother, there was less significant difference. The mother is predominantly closer to the ideal model than the father in both the cases (when parents are married or separated). In conclusion, it can be stated that children perceive the real father quite distant from the ideal one regarding care and interaction, mainly when parents are separated.

Keywords: Perception; children; parental care; systemic.
\end{abstract}

O conceito de família, do ponto de vista científico, é bastante difícil de definir (Araújo, 2002; Aspesi, Dessen \& Chagas, 2005), visto que atualmente muitas modificações são observadas como parte de um processo de mudança de valores e crenças referentes aos papéis dos membros familiares.

A família, entendida como composta por dois genitores e sua prole, apresenta-se hoje de forma mais complexa. O arranjo familiar conhecido como modelo "tradicional", constituído pelo par conjugal e os filhos, quer a mulher desenvolva trabalhos fora do lar ou não, predominou durante muito tempo em nossa história, mas nas últimas décadas vem sendo substituído por outros modelos (Araújo, 2002; Aspesi et al., 2005; Bilac, Oliveira \& Muzskat, 2000).

\footnotetext{
"Endereço para correspondência: Universidade Federal de Santa Catarina, Centro de Filosofia e Ciências Humanas, Departamento de Psicologia,Campus Universitário, Núcleo de Estudos e Pesquisas em Desenvolvimento Infantil Trindade, Florianopolis, SC, 88049-900. Caixa-Postal: 476. Tel.: (048) 3721 8606; Fax: (O48) 3331 1975. E-mail mvieira@cfh.ufsc.br
}

A modernização pode ser considerada como uma das principais causas para a rápida ruptura com o modelo de família tradicional (Souza, 1997). O arranjo familiar "nãotradicional”, famílias que diferem da família padrão, é cada vez mais freqüente. Um exemplo desse arranjo são as famílias monoparentais, sendo inúmeras as crianças vivendo com pais solteiros ou divorciados. Outro exemplo são os pais recasados, cujos filhos convivem ou não com o novo cônjuge do pai ou da mãe, e com os irmãos dessas novas uniões ou de uniões anteriores (Araújo, 2002; Aspesi et al., 2005; Cusinato, 1996; Wagner, Ribeiro, Arteche \& Bernholdt, 1999).

Definições contemporâneas de família a partir da perspectiva Ecopsicológica ${ }^{1}$ estipulam alguns pressupostos: (a) a definição de família deve ser baseada na opinião de seus membros, considerando a afetividade e a proximidade como critério de composição da mesma; (b) tipos e possibilidades 
diversas existem, sem que se registre uma forma única de configuração. De acordo com essa abordagem, familiares são aqueles com os quais se mantêm um vínculo baseado na intimidade e nas relações intergeracionais (Araújo, 2002; Aspesi et al., 2005).

A respeito da pluralidade de formas conjugais e familiares contemporâneas, Diniz (1999) afirma que os novos estilos matrimoniais surgem da inserção de ambos os cônjuges no mercado de trabalho. A inserção da mulher no mercado de trabalho acarretou mudanças nas famílias contemporâneas, exigindo do homem o desempenho de um novo papel no subsistema familiar.

Na perspectiva sistêmica, a família não é tida como um conjunto de díades separadas, nem o desenvolvimento infantil como um processo de aquisição de padrões sociais do ambiente externo - microssistema. Cada membro é incorporado dentro do sistema familiar, influenciando-o e alterando-o como um todo e sofrendo interferência dos demais sistemas (Aspesi et al., 2005; Bronfenbrenner, 2002). Além disso, a família é vista como um microssistema que integra e está contido em sistemas maiores que a influenciam (Bronfenbrenner, 2002). O sistema ecológico é composto por cinco subsistemas que podem ser visualizados como um local de estruturas encaixadas, uma dentro da outra - como um conjunto de bonecas russas. Tais estruturas são, do nível mais profundo ao mais externo: o Microssistema, o Mesossistema, o Exossistema, o Macrossitema e o Cronossistema (Bronfenbrenner, 1994).

Nesse sentido, Lewis e Dessen (1999) consideram que os padrões de paternidade podem estar sistematicamente relacionados a padrões de interação marital. Também aceitam que possa haver similaridades entre pais e mães em seus modos de cuidar, estilos de ensinar e em suas práticas disciplinares. Paternidade e maternidade são experiências compartilhadas pelos pais, mas que podem também acarretar tensão na relação conjugal, em especial nos momentos de transição ou conflito familiar (Lewis \& Dessen, 1999; Sayer, Bianchi \& Robinson, 2004; Stueve \& Pleck, 2003).

O conceito de cuidado parental é mais complexo do que pode parecer. Para Lewis e Dessen (1999), particularmente na infância, quando as rotinas podem ser alteradas rapidamente, em especial durante períodos de mudanças intensas no desenvolvimento da criança, o conceito pode ser relativo e complexo. Portanto, muitas e variadas influências sobre o comportamento de cuidado parental podem ser decorrentes, por exemplo, de mudanças associadas à rotina de uma nova escola, alterações nos compromissos de mães e pais fora de casa ou pela separação do casal.

O aumento do número de divórcios é uma das principais mudanças sociais que ocorre em nações industriais, acarretando certo distanciamento do pai em relação às responsabilidades para com as crianças (Sanson \& Wise, 2001; Smyth, Caruana \& Ferro, 2003). Para Lewis e Dessen (1999), após o divórcio, 50\% dos homens perdem totalmente o contato com suas crianças. Segundo os mesmos autores, esses pais que se afastam completamente dos fi- lhos tendem a ser aqueles que mantinham pouco contato com suas crianças durante o casamento ou, em outro extremo, aqueles que tinham relações tão íntimas com os filhos, que se sentem impedidos de exercer a paternidade em tempo parcial.

Por outro lado, pressupostos teóricos da abordagem sistêmica permitem o entendimento do conceito de percepção como uma maneira subjetiva que o indivíduo tem de ver e entender o mundo, especialmente as relações humanas e os papéis das outras pessoas e o seu próprio em um contexto ecológico específico. Nesse sentido, a percepção está associada às relações que se estabelecem e aos papéis desempenhados e observados pelo indivíduo no contexto do qual faz parte (Bronfenbrenner, 2002).

Bronfenbrenner (2002) considera que os papéis desempenhados por uma pessoa tendem a evocar percepções, atividades e padrões de inter-relação. Nesse sentido, devese considerar que conteúdos integrantes da imaginação e da idealização podem estar presentes na evocação de percepções pelo desempenho de papéis.

As percepções das crianças sobre comportamentos parentais de cuidado são compreendidas a partir de suas atividades, papéis e relações humanas (subjetivas e objetivas) estabelecidas com os próprios pais. Devem ser consideradas igualmente suas capacidades, necessidades e desejos para a investigação sobre como elas percebem os papéis materno e paterno de cuidado, especialmente no contexto familiar.

Com base nestes princípios, as percepções destes sujeitos de estudo sobre cuidado parental são abordadas tanto ao nível real quanto ideal. Entende-se por real o que existe realmente, verdadeiro ou relativo às preocupações e atividades diárias e rotineiras. A realidade pode ser definida como uma qualidade pertencente a fenômenos que reconhecemos terem uma existência independente de nossa própria volição (Berger \& Luckmann, 2000).

Por ideal, aceita-se aquilo que é relativo à idéia, que só existe no pensamento, que possui em grau superlativo, as qualidades positivas de sua espécie, ou que se ajusta exatamente a um modelo simbólico. Berger e Luckmann (2000) definem os processos simbólicos como processos de significação que se referem a realidades diferentes das pertencentes à experiência da vida cotidiana, contendo todos os significados socialmente objetivados e subjetivamente reais.

Dessen e Braz (2000) estudaram o comportamento paterno ideal na percepção das mães e dos pais. Para as mães, encontraram que a participação ideal do pai na vida familiar implicaria: (a) oferecer atenção, carinho, apoio e compreensão à mãe (33\%) e aos filhos (13\%); (b) cuidar dos filhos (13\%); (c) não bater, não "implicar" com a mãe e não beber (13\%) e, (d) ficar em casa com a família, não sair só e não chegar tarde (33\%). Quanto aos pais, responderam que seu papel ideal seria: (a) oferecer atenção, carinho, apoio e compreensão à mãe e à família (53\%); (b) oferecer atenção, carinho, cuidados e impor regras de correção aos filhos $(87 \%)$. Apenas $7 \%$ dos pais relataram a importância de auxiliar nas tarefas domésticas e $20 \%$ afirmaram que 
faz parte do desempenho ideal do papel paterno responsabilizar-se pelo sustento da família.

O estudo de Dessen e Braz (2000) sugere que para a mãe, o pai é apontado dentre os familiares como a principal fonte de apoio (quando ele está presente no meio familiar). O pai considera que o suporte econômico que ele provê constitui-se no apoio de maior relevância para o bem-estar dos filhos. Esses dados sugerem que pais e mães têm valores diferentes, possivelmente associados aos papéis de gênero feminino e masculino. Em concordância com estudos anteriores (Coelho, 2000; Lewis, 2000; Lewis \& Dessen, 1999), Dessen e Braz (2000) concluem que, embora haja uma forte tendência a mudanças nos valores referentes aos papéis atribuídos ao pai nos tempos atuais, os relatos dos pais e das mães desse estudo sugerem que as mulheres continuam valorizando um papel de "guardiã" da situação emocional e afetiva, enquanto que os homens atribuem ainda ao papel paterno uma função ampla de provedor.

Gomes e Resende (2004) investigaram a figura real do pai, presente corporal e afetivamente, que se depara com a demanda subjetiva, imposta pela exigência de revisão de seu papel no mundo contemporâneo. Os resultados são indicativos de que os filhos que sentiram ausência de figura paterna calorosa, considerando-a severa e autoritária, idealizaram um pai mais tolerante e afetuoso, presente e capaz de se aproximar fisicamente do filho.

Para este estudo, a percepção de sujeito está associada ao subsistema familiar. É a interação que, constituindo o sistema, torna seus elementos interdependentes: cada parte está relacionada às demais, de forma que uma mudança numa delas acarretará mudanças nas demais. Dessa forma, para que se compreenda o comportamento das partes, torna-se indispensável considerar suas percepções sobre relações.

Nesse sentido, pretende-se comparar as percepções que as crianças têm a respeito do comportamento real de cuidado parental, que engloba as atividades diárias nas quais interagem com o pai e a mãe, com as expectativas idealizadas, que se constituem por idéias relativas a um modelo, o mais aproximado do ideal, do desejado. Além disso, buscase verificar se há diferenças entre as percepções de filhos cujos pais vivem juntos em relação àquelas dos que convivem somente com a mãe.

\section{Método}

\section{Participantes}

Participaram do estudo 213 sujeitos matriculados regularmente em duas escolas da rede municipal de ensino, com idade entre 10 e 11 anos. Dentre os participantes do estudo, $67 \%$ das crianças conviviam com ambos os pais, tendo estes uma união estável (legalmente casados ou não) e $33 \%$ delas residiam somente com a mãe, sendo os pais legalmente separados ou não. A partir desses critérios, os questionários foram designados, respectivamente, por pai casado, mãe casada, pai separado, mãe separada (apesar dos termos não serem exatamente apropriados, foram utilizados para facilitar a diferenciação e descrição).

\section{Instrumentos}

O questionário original foi elaborado por Marc Bornstein et al. para mensurar como a mãe compreende maternagem real e ideal e paternagem real e ideal, e posteriormente adaptado por Maria Lucia Seild de Moura e Rodolfo de Castro Ribas $\mathrm{Jr}^{2}$ para o Brasil (Seidl de Moura \& Ribas Jr., 2003).

Para a presente pesquisa foram selecionadas algumas das questões fechadas mais representativas de cada categoria: (a) cuidados diretos ("prática de cuidado parental" e "percepção sobre cuidado parental"); (b) cuidados indiretos ("integração familiar"); (c) interação social instrutiva ("disciplinas e regras" e "coerção emocional parental”); e, (d) interação social calorosa ("brincadeira entre pais e filhos" e "afetividade parental"). As questões foram reformuladas na escrita, para adaptar o questionário à linguagem infantil (Romanelli \& Biasoli-Alves, 1998) a partir da coleta de dez questionários de pré-testes (Barbetta, 2004). A partir dos resultados dos pré-testes, algumas questões foram modificadas da ordem inversa de escrita para a direta e da negativa para a afirmativa.

Ao final da adaptação para este estudo, obteve-se um instrumento de 28 questões no total, sendo 14 delas referentes à paternidade (questionário sobre o pai) e 14 referentes à maternidade (questionário sobre a mãe), cujas perguntas ou afirmativas são fechadas do tipo ordinal, em ordem decrescente, numeradas com itens de respostas de três a um (sempre, às vezes e nunca). Cada questionário contém duas subdivisões, que são pai real (7 questões) e pai ideal ( 7 questões) ou mãe real ( 7 questões) e mãe ideal (7 questões). A média de tempo que as crianças levaram para responder o questionário foi de 30 minutos. A média de sujeitos respondentes foi de 7,6 para cada item dos questionários.

\section{Procedimentos}

Os questionários foram aplicados pela própria pesquisadora, na biblioteca, sempre com grupos de seis crianças. O procedimento de aplicação foi padronizado de acordo com o cabeçalho de apresentação da escala (dados de identificação: iniciais do nome, idade, sexo, situação conjugal parental, idade dos pais e número de irmãos) e foi exposto verbalmente às crianças. A aplicação dos instrumentos foi realizada em duas etapas. Na primeira, as crianças responderam apenas ao questionário sobre o pai e na segunda, responderam ao questionário sobre a mãe.

A realização da pesquisa foi aprovada pelo Comitê de Ética para Pesquisa em Seres Humanos da Universidade Federal de Santa Catarina (protocolo n 265/O4).

\section{Análise de Dados}

Os dados foram analisados por meio do Statistical Package of Social Sciences (SPSS 10.0). Foi realizada uma análise descritiva dos dados para caracterização da amostra total. Para verificar se havia diferenças entre as médias das cate- 
gorias obtidas, foi utilizada a prova $\mathrm{T}$ das categorias com sinal de Wilcoxon $(\mathrm{T})$.

\section{Resultados}

$\mathrm{Na}$ amostra total houve predominância do sexo feminino (55\% das crianças); $52 \%$ delas tinham 11 anos e o restante, 10 anos; $67 \%$ delas moravam com ambos os pais e o restante, somente com a mãe - alguns destes pais mora- vam na mesma cidade, outros fora e outros quatro já haviam falecido. A idade dos pais variou entre 27 e 68 anos e aproximadamente $60 \%$ das crianças têm um ou dois irmãos.

Na primeira análise dos dados foi verificado se os filhos cujos pais vivem juntos percebem diferenças no cuidado parental entre o pai real e o pai ideal. Os resultados da prova de Wilcoxon (T) calculados nas subescalas pai real casado e pai ideal casado são descritos na Tabela 1 .

Tabela 1

Valores da Prova T atribuídos pelas Crianças na Escala Pai Casado Real e Ideal

\begin{tabular}{|c|c|c|c|}
\hline \multirow{2}{*}{$\begin{array}{l}\text { Pai Real Casado x Pai Ideal Casado } \\
\text { Questões }\end{array}$} & \multicolumn{2}{|c|}{ Soma da Prova de Sinais $(\mathrm{T})$} & \multirow[t]{2}{*}{$P$} \\
\hline & Negativa & Positiva & \\
\hline 1. Prática de cuidado parental & 88 & 165 & 0,162 \\
\hline 2. Percepção sobre cuidado parental & 139,5 & 325,5 & $0,028^{*}$ \\
\hline 3. Integração familiar & 37 & 666 & $\mathrm{O}, \mathrm{OOO}^{*} *$ * \\
\hline 4. Disciplina e regras & 72 & 81 & 0,808 \\
\hline 5. Coerção emocional parental & 143,5 & 132,5 & 0,854 \\
\hline 6. Brincadeira entre pais e filhos & 57,5 & 293,5 & $\mathrm{O}, \mathrm{OO} 1^{*} *$ \\
\hline 7. Afetividade parental & 51 & 120 & 0,101 \\
\hline
\end{tabular}

Notas. $n=142 ; *^{*} \leq 0,05 ; * * p \leq 0,01$

Através da análise dos dados, constataram-se diferenças entre três pares de questões (2, 3 e 6). Estes resultados indicam que os filhos de pais casados percebem diferenças entre o pai real e o ideal. Os filhos têm expectativas maiores em relação ao pai ideal no que diz respeito à atenção do pai para as necessidades de cuidado da criança, que envolvem a atenção do pai para aspectos referentes à higiene, à alimentação, à saúde e à cognição (questão 2, da categoria cuidados diretos); aos passeios e diversão, que abrange aspectos de estímulos à integração social e cul- tural (questão 3, cuidados indiretos) e também em aspectos referentes à interação calorosa pai-criança, como jogos e brincadeiras (questão 6, da categoria interação social calorosa).

A segunda análise estatística foi realizada para mensurar possíveis diferenças entre as percepções reais e ideais das crianças sobre o pai, quando os pais são separados. Os resultados da prova de Wilcoxon (T), calculados nas subescalas pai real separado e pai ideal separado, são descritos na Tabela 2 .

Tabela 2

Valores da Prova T atribuídos pelas Crianças na Escala Pai Separado Real e Ideal

\begin{tabular}{|c|c|c|c|}
\hline \multirow{2}{*}{$\begin{array}{l}\text { Pai Real Separado x Pai Ideal Separado } \\
\text { Questões }\end{array}$} & \multicolumn{2}{|c|}{ Soma da Prova de Sinais $(\mathrm{T})$} & \multirow[t]{2}{*}{$P$} \\
\hline & Negativa & Positiva & \\
\hline 1. Prática de cuidado parental & $\mathrm{O}$ & 378 & $\mathrm{O}, \mathrm{OOO}^{*} *$ * \\
\hline 2. Percepção sobre cuidado parental & 5,5 & 319,5 & $\mathrm{O}, \mathrm{OOOO}^{*} *$ \\
\hline 3. Integração familiar & $\mathrm{O}$ & 351 & $\mathrm{O}, \mathrm{OOO}^{*} *$ \\
\hline 4. Disciplina e regras & 27 & 273 & $\mathrm{O}, \mathrm{OOOO}^{*} *$ \\
\hline 5. Coerção emocional parental & 114 & 211 & 0,175 \\
\hline 6. Brincadeira entre pais e filhos & 6,5 & 318 & O,OOO米米 \\
\hline 7. Afetividade parental & 18 & 192 & $\mathrm{O}, \mathrm{OO} 1^{*} *$ * \\
\hline
\end{tabular}

Notas. $n=71$; *** $p \leq 0,01$.

Pelos resultados da prova $\mathrm{T}$, quando os pais são separados, há diferença significativa entre o pai real e o ideal. Pode-se dizer que quando os pais são separados, os filhos percebem o pai real bastante diferente do pai ideal, esperando deste mais cuidados diretos, tais como suprir e es- tar atento às necessidades básicas ligadas à alimentação, vestuário, medicação e materiais escolares da criança (questões 1 e 2 , da categoria cuidados diretos). As crianças esperam também sair mais para passear e se diver tir em companhia do pai (questão 3, da categoria cuidados indiretos); 
pensam que seja ideal receber maior orientação sobre regras de comportamento (questão 4, da categoria interação social instrutiva) e gostariam que o pai real brincasse um pouco mais com elas e demonstrasse mais carinho para aproximar-se do ideal de cuidado delas (questões 6 e 7, da categoria interação social calorosa).

Tabela 3
A terceira análise estatística foi realizada para mensurar possíveis diferenças entre as percepções reais e ideais dos filhos sobre a mãe, quando os pais são casados. As subescalas foram nomeadas, respectivamente, por mãe real casada e mãe ideal casada, e constituem a escala mãe casada, cujos resultados obtidos na prova de Wilcoxon (T) são descritos na Tabela 3.

Valores da Prova T atribuídos pelas Crianças na Escala Mãe Casada Real e Ideal

\begin{tabular}{lccl}
\hline Mãe Real Casada x Mãe Ideal Casada & Soma da Prova de Sinais $(\mathrm{T})$ & $\mathrm{P}$ \\
\hline Questões & Negativa & Positiva & \\
1. Prática de cuidado parental & 35 & 56 & 0,405 \\
2. Percepção sobre cuidado parental & 25 & 30 & 0,782 \\
3. Integração familiar & 99 & 429 & 0,00 * $^{*}$ \\
4. Disciplina e regras & 45,5 & 32,5 & 0,564 \\
5. Coerção emocional parental & 114,5 & 95,5 & 0,697 \\
6. Brincadeira entre pais e filhos & 62 & 466 & $0,000^{*} *$ \\
7. Afetividade parental & 18 & 48 & 0,132
\end{tabular}

Notas. $n=142$ * $^{*} p \leq 0,01$.

Na prova de Wilcoxon (T) houve diferença estatisticamente significativa apenas entre dois pares de médias (3 e 6). A partir de todos os resultados, pode-se afirmar que, em termos reais, não há predominância de diferenças nas percepções dos filhos sobre aspectos referentes ao cuidado e à interação que a mãe proporciona, quando ela convive com o pai da criança. Somente no que diz respeito a sair para passear, divertir-se (questão 3, da categoria cui- dados indiretos) e a brincar (questão 6, da categoria interação social calorosa), as crianças esperam mais cuidado e interação da mãe real em relação à ideal.

A quarta análise estatística foi realizada para verificar se os filhos cujos pais são separados percebem diferenças entre a mãe real e a ideal. Os resultados da prova de Wilcoxon (T), calculados nas subescalas mãe real separada e mãe ideal separada são descritos na Tabela 4 .

Tabela 4

Valores da Prova T atribuídos pelas Crianças na Escala Mãe Separada Real e Ideal

\begin{tabular}{lccl}
\hline Mãe Real Separada x Mãe Ideal Separada & Soma da Prova de Sinais (T) & $\mathrm{P}$ \\
\hline Questões & Negativa & Positiva & \\
1. Prática de cuidado parental & 7 & 14 & 0,414 \\
2. Percepção sobre cuidado parental & 6 & 9 & 0,655 \\
3. Integração familiar & 6,5 & 71,5 & $0,004^{*}$ \\
4. Disciplina e regras & 2 & 4 & 0,564 \\
5. Coerção emocional parental & 139 & 51 & 0,056 \\
6. Brincadeira entre pais e filhos & 9 & 162 & $0,000^{*} *$ \\
7. Afetividade parental & 16,5 & 38,5 & 0,206 \\
\hline
\end{tabular}

Notas. $n=71 ; * \leq 0,05 ; * * 1$; 0,01 .

Na prova de Wilcoxon (T) houve diferença estatisticamente significativa entre dois pares de médias (3 e 6). A partir de todos os resultados, pode-se afirmar que na maioria dos aspectos investigados não há predominância de diferenças entre as expectativas ideais dos filhos em relação à mãe, mesmo que ela não conviva com o pai da criança. Somente no que se refere a sair para passear, divertir-se (questão 3, da categoria cuidados indiretos) e a brincar (questão 6, da categoria interação social calorosa), as expectativas ideais das crianças são maiores em relação à mãe.

\section{Discussão}

As alterações que vêm ocorrendo no desempenho dos papéis parentais dentro do subsistema familiar devem ser consideradas como associadas e em consonância com ca- 
racterísticas de um contexto mais amplo - o Macrossistema. Aspectos da cultura, mudanças sócio-econômicas e fatos históricos devem ser considerados como determinantes de tais alterações. O próprio sistema espaço temporal (Cronossistema), que abrange mudanças relativas ao tempo precisa ser levado em conta. Devem ser consideradas não somente as características das pessoas, como também do ambiente em que elas vivem, como por exemplo, quando ocorrem mudanças no interior da pessoa, no curso de vida e da estrutura familiar, no status sócioeconômico, no trabalho, local de residência, entre outras (Bronfenbrenner, 1994, 2002).

A respeito destas mudanças, resultados semelhantes aos do estudo de Diniz (1999) sobre a inserção da mulher no mercado de trabalho e suas conseqüentes alterações no desempenho dos papéis parentais, principalmente no papel atribuído ao homem dentro do sistema familiar, podem ser percebidos neste estudo, no qual pai e mãe, quando convivem, desempenham papéis de cuidado e de interação de forma muito semelhante na percepção dos filhos.

Neste estudo, com relação às possíveis diferenças na percepção dos filhos a respeito do cuidado parental entre famílias de arranjo tradicional e monoparentais, observase que as crianças atribuem um papel ideal ampliado para o pai no que se refere à atenção para o cuidado, esperando dele também mais diversão e brincadeiras. Em contrapartida, apesar das mães estarem inseridas no mercado de trabalho, representando cada vez mais freqüentemente um papel de provedora do lar na percepção das crianças, elas correspondem de maneira mais satisfatória às expectativas dos filhos, mas devem também estar mais presentes na brincadeira e na diversão.

A este respeito, e em concordância com as afirmações de Lewis (2000) sobre uma possível tendência à mudança nos valores atribuídos ao papel paterno na atualidade, neste estudo as crianças atribuem e têm expectativas que superam as atribuições de cuidado paterno conhecidas tradicionalmente, principalmente no que diz respeito ao pai representar apenas o papel de provedor. À mãe também é atribuído tal papel e os filhos esperam mudanças de ambos os membros do par parental. Nesse sentido, segundo Warin, Solomon, Lewis e Langford (1999), nas famílias em que a mulher também trabalha fora (cônjuges duploganho), ocorrem maior divisão de tarefas no lar, ou seja, divisão dos afazeres domésticos e nos cuidados diários com os filhos. O compartilhar dessas tarefas reporta ao princípio sistêmico da causalidade circular em que a mudança no comportamento de um membro da família gera mudanças em cadeia, isto é, afeta o comportamento dos demais, e nesse caso, o do pai. Portanto, pode-se pensar que a tarefa dos pais em identificar, assumir e compartilhar novos papéis ainda constitui um desafio ao subsistema familiar em busca do equilíbrio necessário e que aspectos como diver são e brincadeiras são fundamentais na percepção dos filhos.

Pelos resultados do presente estudo, conclui-se que quando o pai e a mãe vivem juntos e compartilham o cuidado dos filhos, estes tendem a percebê-los de maneira bastante semelhante. Em termos reais, as crianças esperam que o pai e a mãe estejam mais presentes na diversão e nas brincadeiras para que se aproximem totalmente do seu ideal. Esse ideal sugere que as crianças percebem a integração (Cuidados Indiretos) e a interação pela brincadeira (Interação Social Instrutiva) como papéis a serem desempenhados por ambos os pais. Tais percepções dos filhos demonstram a importância dos pais em suprir necessidades características da infância, que são o desejo de brincar, interagir, sorrir e se divertir.

Além disso, as crianças percebem que o pai deveria prestar mais atenção às necessidades de cuidado para ficar mais próximo do ideal. Contudo, em outros aspectos do cuidado e da interação, eles desempenham e compartilham seus papéis satisfatoriamente. Pleck (1997) e Veneziano (2003) encontraram resultados semelhantes ao sugerir que o pai tem tido um papel cada vez mais ampliado e importante para o desenvolvimento da sua criança, sendo a presença paterna, com o respectivo envolvimento afetivo e caloroso do pai, determinante para o desenvolvimento físico e psíquico saudável do filho. Para Veneziano, apesar de a disponibilidade física do pai ser fundamental por favorecer a aproximação com sua criança, é o comportamento "caloroso", aquele carregado de afeto e carinho, que influencia de maneira positiva o desenvolvimento infantil.

Muitos autores consideram que a paternidade e a maternidade devem ser experiências compartilhadas pelos pais (Lewis \& Dessen, 1999; Sayer et al., 2004; Stueve \& Pleck, 2003). Através do presente estudo, constata-se que o fato de os pais viverem juntos pode ser determinante para que os filhos percebam de forma mais equilibrada o compartilhar da tarefa parental.

Bronfenbrenner (1994, 2002) considera que os estudos dos subsistemas familiares devem incluir, além das díades mãe-criança, também as díades pai-criança, pois na família há diferenças no funcionamento das díades, que podem ser determinadas pela presença ou ausência física de um ou outro membro familiar. Nesse sentido, constata-se diferença importante entre as percepções dos filhos sobre a díade pai-criança e a díade mãe-criança quando os pais não vivem juntos. Nesse caso, o pai real é percebido de maneira bastante diferente do ideal. Segundo as percepções dos filhos, ele proporciona menos cuidado direto, atenção às necessidades infantis, interação pelo carinho, diversão, brinquedo e orientação. Da mesma forma, o pai que vive com a família diferencia-se bastante do que não vive. $\mathrm{O}$ cuidado real que a mãe dispensa aos filhos aproxima-se bastante do cuidado que estes percebem como ideal, mesmo quando a mãe não compartilha a tarefa parental com o pai no convívio.

O afastamento do pai após a separação, que também é percebido pelas crianças deste estudo, vem sendo investigado por diversos autores com resultados semelhantes (Blankenhorn,1997; Dessen, 1997; Lewis \& Dessen, 1999; Smyth et al., 2003; Souza, 2000). Lamb (1997) considera que as crianças podem sofrer, após o divórcio de seus pais, um declínio na qualidade da relação com o membro parental que se afasta, com diminuição do suporte psico- 
lógico que recebe de um ou de ambos os pais. Por outro lado, quando as relações parentais são construtivas podem ter influência positiva, mesmo na separação conjugal, ensinando às crianças valiosas lições pelas expressões de conflitos e negociações.

Quanto aos filhos, não se pode desconsiderar que as suas expectativas ideais contêm reflexos da cultura e por conseqüência do Macrossistema no qual estão inseridas. Nesse sentido, à medida que o padrão ideal de paternidade contemporâneo é de um pai mais envolvido e ativo com seus filhos, que brinca, instrui e leva os filhos para passear (Pleck \& Pleck, 1997), os filhos idealizam e atribuem este papel ao pai, ainda que ele não conviva com a criança.

\section{Considerações Finais}

No atual contexto ecológico familiar a mulher, que está inserida no mercado de trabalho, continua desempenhando com versatilidade os múltiplos papéis que lhe são atribuídos como mãe, esposa, dona-de-casa e, parece suprir as demandas real e ideal de forma predominantemente satisfatória na opinião dos filhos participantes deste estudo, mesmo quando ela é a única responsável pelo cuidado destes.

O homem, por sua vez, começa a desempenhar novos e diferentes papéis junto à família. Contudo, os filhos esperam ainda mais para que o pai se aproxime de seu ideal, principalmente quando os pais se separam. Os papéis atribuídos ao pai pelas crianças deste estudo estão relacionados a expectativas ideais mais amplas no que se refere ao cuidado e à interação, principalmente quando os pais são separados. Isto demonstra que, mesmo quando os pais não vivem juntos, os filhos atribuem um papel importante ao pai nos cuidados diretos, indiretos e na interação social instrutiva e calorosa com ele. Nesse sentido, parece que o homem precisa encontrar uma forma de suprir tais demandas dos filhos, desempenhando este novo papel com estratégias novas e específicas, visto que a quantidade de famílias com arranjo monoparental matriarcal é expressiva no contexto atual.

Movimentos, atribuições de papéis e as próprias expectativas dos filhos em relação aos membros do par parental, podem ser compreendidos como uma busca constante de equilíbrio, característica do subsistema familiar e cujos fins últimos são a adaptação e o desenvolvimento do sistema familiar como um todo.

\section{Referências}

Araújo, V. F. O. A. (2002). Reflexões sobre a família e educação na modernidade. Estilos da Clínica, 7(12), 100-111.

Aspesi, C. C., Dessen, M. A., \& Chagas, J. F. (2005). A ciência do desenvolvimento humano: Uma perspectiva interdisciplinar. In M. A. Dessen \& A. S. L. Costa Jr. (Eds.), A ciência do desenvolvimento humano: Tendências atuais e perspectivas futuras (pp. 19-36). Porto Alegre, RS: Artmed.

Barbetta, P. A. (2004). Estatística aplicada às ciências sociais. Florianópolis, SC: Editora da Universidade Federal de Santa Catarina
Berger, P. L., \& Luckmann, T. (2000). A construção social da realidade: Tratado de sociologia do conhecimento. Petrópolis, RJ: Vozes.

Bilac, E. D., Oliveira, M. D., \& Muzskat, M. (2000). O homem de família: Conjugalidade e paternidade em camadas médias nos anos 90. In Anais do XXIV Encontro Anual da ANPOCS, Petrópolis, RJ.

Blankenhorn, D. (1997). Faterless society. Quadrant, 41(12), 9-16.

Bronfenbrenner, U. (1994). Ecological models of human development. Encyclopedia of Education, 3, 1643-1647.

Bronfenbrenner, U. (2002). A ecologia do desenvolvimento humano: Experimentos naturais e planejados (M. A. V. Veronese, Trad.). Por to Alegre, RS: Ar tes Médicas. (Original publicado em 1994) Coelho, S. V. (2000). As transformações da família no contexto brasileiro: Uma perspectiva das relações de gênero. Psique, $16,7-25$.

Cusinato, M. (1996). Research on family resources and needs across the world. Milan, Itália: LED.

Dessen, M. A. (1997). Desenvolvimento familiar: Transição de um sistema triádico para poliádico. Temas em Psicologia: Processos Sociais e Desenvolvimento, 3, 51-61.

Dessen, M. A., \& Braz, M. P. (2000). Rede social de apoio durante transições familiares decorrentes do nascimento de filhos. Psicologia: Teoria e Pesquisa, 16(3), 22 1-231.

Diniz, G. R. S. (1999). Homens e mulheres frente à interação casamento-trabalho: Aspectos da realidade brasileira. In T. F. Carneiro (Ed.), Casal e família (pp. 31-54). Rio de Janeiro, RJ: NAU

Gomes, A. J. S., \& Resende, V. R. (2004). O pai presente: O desvelar da paternidade em uma família contemporânea. Psicologia: Teoria e Pesquisa, 20(2), 119-125.

Lamb, M. E. (1997). The role of the father in child development. New York: John Wiley \& Sons.

Lewis, C. (2000). A man's place in the home: Fathers and families in the UK. New York: Joseph Rowntree Foundation.

Lewis, C., \& Dessen, M. A. (1999). O pai no contexto familiar. Psicologia: Teoria e Pesquisa, 15(1), 9-16.

Pleck, J. H. (1997). Paternal involvement: Levels, sources, and consequences. In M. E. Lamb (Ed.), The role of the father in child development (pp. 65-103). New York: John Wiley \& Sons.

Pleck, J. H., \& Pleck, E. H. (1997). Fatherhood ideals in the United States: Historical dimensions. In M. E. Lamb (Ed.), The role of the father in child development (pp. 33-48). New York: John Wiley \& Sons.

Romanelli, G., \& Biasoli-Alves, Z. M. M. (1998). Diálogos metodológicos sobre prática de pesquisa. Ribeirão Preto, SP: Legis Summa.

Sayer, L. C., Bianchi, S. M., \& Robinson, J. P. (2004). Are parents investing less in children? Trends in mother's and father's time with children. The American Journal of Sociology, 1O(1), 43-49.

Sanson, A., \& Wise, S. (2001). Children and parenting: The past hundred years. Family Fathers, 3, 36-46.

Seidl de Moura, M. L., \& Ribas, R. C., Jr. (2003). Algumas informações sobre o instrumento estilo materno e paterno. Relatório parcial do projeto Interação mãe-bebê e desenvolvimento infantil: Um estudo longitudinal e transcultural. Rio de Janeiro, RJ: Universidade do Estado do Rio de Janeiro. Material não publicado.

Smyth, B., Caruana, C., \& Ferro, A. (2003). Shared parenting: The views of separated parents with 50:50 care arrangements: What are the motives, arrangements, and reflections of separated parents who spend equal time with their children? This paper provides some insights. Family Matters, 65, 48-55. 
Souza, R. M. (1997). A criança na família em transformação: Um pouco de reflexão e um convite à investigação. Revista de Psicologia, 5, 33-51.

Souza, R. M. (2000). Depois que papai e mamãe se separaram: Um relato dos filhos. Psicologia: Teoria e Pesquisa, 16(3), 203-2 11.

Stueve, J. L., \& Pleck, J. H. (2003). Father's narratives of arranging and planning: Implications for understanding paternal responsibility. Fathering; 1(1), 51-71.

Veneziano, R. A. (2003). The importance of paternal warmth Cross-Cultural Research, 37, 265-281.

Wagner, A., Ribeiro, L. S., Arteche, A. X., \& Bernholdt, E. A. (1999). Configuração familiar e o bem-estar psicológico dos adolescentes. Psicologia: Reflexão e Crítica, 12(1), 147-156.

Warin, J., Solomon, Y., Lewis, C., \& Langford, W. (1999). Fathers, work and family life. London: FPSC. 